\title{
Neural Network Modeling for Ni(II) Removal fromAqueous System Using Shelled Moringa Oleifera Seed Powder as an Agricultural Waste
}

\author{
Kumar Rohit Raj ${ }^{1}$, Abhishek Kardam ${ }^{1}$, Jyoti Kumar Arora ${ }^{2}$, \\ Man Mohan Srivastava ${ }^{1}$, Shalini Srivastava ${ }^{1}$ \\ ${ }^{1}$ Department of Chemistry, Faculty of Science, Dayalbagh Educational Institute, Agra, India \\ ${ }^{2}$ Department of Mathematics, Technical College, Dayalbagh Educational Institute, Agra, India \\ E-mail:smohanm@rediffmail.com \\ Received November 10, 2009; revised December 1, 2009; accepted January 30, 2010
}

\begin{abstract}
A single-layer Artificial Neural Network (ANN) model was developed to predict the removal efficiency of $\mathrm{Ni}(\mathrm{II})$ ions from aqueous solution using shelled Moringa Oleifera seed (SMOS) powder. Batch experiments resulted into standardization of optimum conditions: biomass dosage $(4.0 \mathrm{~g}), \mathrm{Ni}(\mathrm{II})$ concentration $(25 \mathrm{mg} / \mathrm{L})$ volume $(200 \mathrm{~mL})$ at $\mathrm{pH} 6.5$. A time of forty minutes was found sufficient to achieve the equilibrium. The ANN model was designed to predict sorption efficiency of SMOS for target metal ion by combining back propagation (BP) with principle component analysis. A sigmoid axon was used as transfer function for input and output layers. The Levenberg-Marquardt Algorithm (LMA) was applied, giving a minimum mean squared error (MSE) for training and cross validation at the ninth place of decimal.
\end{abstract}

Keywords: Artificial Neural Networks, Biosorption, Moringa Oleifera, Ni(II) Removal

\section{Introduction}

The pattern of industrial activity alters the natural flow of materials and introduces chemicals in their effluents [1]. Most of these effluents contain toxic substances especially heavy metals. The heavy metals are of special concern because they are non-degradable and thus persistent. The removal of heavy metals from wastewater has recently become the subject of considerable interest due to more strict legislations introduced to control water pollution. Current methodologies such as chemical precipitation, electro floatation, ion-exchange and reverse osmosis have been used for the removal of heavy metals [2]. Activated carbon is also regarded as an effective adsorbent for removal of metal ions from water [3]. However, these processes are economically non-feasible especially for the developing countries [4].

Biomaterials have gained much importance for decontamination of water which involves processes that reduce overall treatment cost through the application of wastes like bagasse pith, wood, saw dust and other agricultural wastes [5-7]. They are particularly attractive as they lessen reliance on expensive water treatment chemicals, negligible requirements of transportation and thus offer- ing genuine, local resources as alternate solutions to tackle local issues of water quality problems. This novel approach is competitive, effective and low cost. Agricultural wastes that are available in large quantities have enough potential to be used as biosorbents in an environment friendly manner. Regeneration of the biosorbents further increases the cost effectiveness of the process thus warrants its future success following the concept of Green Chemistry which is a new principle guiding the next generation products and processes [8].

$\mathrm{Ni}(\mathrm{II})$ has been recognized as one of the hazardous heavy metals commonly used in mining, acid battery manufacturing, metal plating etc. [9,10]. Significant quantities of nickel-containing waste water are introduced into water bodies from the effluents of nickel plating plants, silver refineries, zinc based casting industries and storage batteries [11]. Higher concentration of $\mathrm{Ni}(\mathrm{II})$ causes cancer of lungs, kidneys, gastrointestinal distress, nausea, vomiting, pulmonary fibrosis, renal edema and skin dermatitis [12]. These harmful effects of Ni(II) necessitate its removal from waste waters before release into streams.

To achieve an optimum management for any control measure, the concept of modeling for an efficient opera- 
tion and design should be developed. ANN utilizes interconnected mathematical neurons to form a network that can model complex functional relationship [13]. In recent years, ANN have been used as a powerful modeling tool in various processes such as membrane filtration, gas separation, ultra filtration, reverse osmosis etc. [1416].

In continuation of our work on biosorption of toxic metals using agricultural waste from waste water [17-20], the present paper describes the abatement of $\mathrm{Ni}$ (II) ions from aqueous system using shelled Moringa Oleifera seed (SMOS) powder. Moringa Oleifera, a multidimensional tropical plant that survives in heat, desiccating dryness and destitute soils is deemed to be an efficient biosorbents for metal removal than other biosorbents previously reported. The paper also reports the applicability of a single-layer ANN model using a back propagation (BP) algorithm to predict the removal efficiency of shelled Moringa Oleifera seed powder (SMOS) for Ni(II) ions. Pursuing benchmark comparisons of BP algorithms, a study was conducted to determine the optimization study to determine the optimal network structure. Experimental data were initially distributed to three subsets; training, validation and testing. Finally, output obtained from the ANN modeling was compared with the experimental data. The present piece of work highlights the possibility of the prediction of sorption efficiency for the metal ions from waste water using SMOS in the range of metal concentration with which lab experiments have not been conducted.

\section{Materials and Methods}

\subsection{Biosorbent Preparation}

Moringa Oleifera Lam. tree was notified in the nearby area of Dayalbagh Educational Institute and the seeds were collected from the target plant. Seeds were washed thoroughly with double distilled water to remove the adhering dirt, dried at $65^{\circ} \mathrm{C}$ for $24 \mathrm{~h}$, crushed and sieved through (105) mesh copper sieves. Shelled Moringa Oleifera seeds (SMOS) were used as biosorbent.

\subsection{Biosorption Studies}

Sorption studies using standard practices were carried out in batch experiments (triplicate) as a function of biomass dosage (2.0-6.0 g), contact time (10-60 $\mathrm{min})$, volume of the test solution (100-300 mL), metal concentration (10-100 mg/L), particle size (105) and $\mathrm{pH}$ (4.5-8.5). A required amount of Ni(II) (Nickel Sulphate, AR grade) was taken in an Erlenmeyer flask and after $\mathrm{pH}$ adjustments, a known quantity of dried biosorbent was added and metal bearing suspensions were kept under magnetic stirring until equilibrium conditions were reached. After shaking, the suspension was allowed to settle. The residual biomass sorbed with metal ion was filtered using Whatman 42 filter paper (Whatman International Ltd., Maid stone, England). Filtrate was collected and subjected for metal ion estimation using Flame atomic absorption spectrometer. Percent metal uptake by the sorbent has been computed using the equation: \% Sorption $=\mathrm{Co}-100 \mathrm{Ce} / \mathrm{Co}$, where $\mathrm{Co}$ and $\mathrm{Ce}$ were the initial and final concentration of metal ions in the solution.

\subsection{Statistical Analysis}

Batch experiments were conducted in triplicates $(\mathrm{N}=3)$ and data represent the mean values. Regression, correlation coefficients, standard deviations have been calculated using SPSS PC + TM statistical package. For the determination of inter group mean values differences, each parameter was subjected to a student " $t$ " test for determining significance level $(\mathrm{p}<0.05)$.

\subsection{Definition of the ANN Model}

A neural network is a massively parallel distributed processor made up of simple processing units, which has a natural propensity for storing experimental knowledge and making it available for use. A neuron is an information processing unit that is fundamental to the operation of a neural network. Neural Network Toolbox Neuro Solution 5 ( mathematical software was used to predict the sorption efficiency. Ninety experimental sets were used to develop the ANN model. A single-layer ANN with sigmoid axon transfer function was used for input and output layers. The data gathered from batch experiments were divided into input matrix and desired matrix. The single layer sigmoid network represents functional relationship between inputs and output, provided sigmoid layer has enough neurons. Levenberg-Marquardt algorithm is fastest training algorithm for network of moderate size, therefore, used in the present study.

\section{Results and Discussions}

\subsection{Sorption Studies}

Table 1 represents soluble Ni(II) ion concentration after sorption on SMOS powder. Sorption studies led to the standardization of the optimum conditions as: $\mathrm{Ni}(\mathrm{II})$ concentration $(25 \mathrm{mg} / \mathrm{L})$, contact time (40 $\mathrm{min})$ and volume $(200 \mathrm{~mL})$ at $\mathrm{pH} 6.5$ for maximum $\mathrm{Ni}$ removal (75.64\%).

The results indicate that the SMOS has considerable potential to be used as biosorbent for metal removal from waste water. Studies, therefore, have been planning to predict the efficiency of SMOS for the removal of Ni(II) using ANN model. 
Table 1. Soluble Ni(II) ion concentration $(\mu \mathrm{M})$ after adsorption on SMOS for Ni(II) as a function of metal concentration and biomass dosage at volume $(200 \mathrm{~mL})$, $\mathrm{pH} 6.5$ and particle size $(105 \mu \mathrm{M})$.

\begin{tabular}{|c|c|c|c|c|c|}
\hline \multirow{2}{*}{$\begin{array}{l}\text { Initial conc. } \\
\qquad(\mu \mathrm{M})\end{array}$} & \multicolumn{5}{|c|}{ Time interval (minutes) } \\
\hline & 10 & 20 & 30 & 40 & 60 \\
\hline \multicolumn{6}{|c|}{ Biomass dosage (2 g) } \\
\hline $03.41 \mathrm{a}$ & $02.73 \pm 0.15^{\mathrm{bx}+\varphi}$ & $02.45 \pm 0.13^{\mathrm{x}^{+}}$ & $02.28 \pm 0.12^{\mathrm{x}^{+}}$ & $02.18 \pm 0.11^{\mathrm{x}^{+}}$ & $02.18 \pm 0.10^{\mathrm{xx}+}$ \\
\hline 17.06 & $11.94 \pm 0.54^{\mathrm{x}^{+}}$ & $10.85 \pm 0.52^{x^{+}}$ & $10.20 \pm 0.51^{\mathrm{x}+}$ & $9.72 \pm 0.48^{x^{+}}$ & $09.69 \pm 0.50^{\mathrm{xx}+}$ \\
\hline 34.12 & $22.01 \pm 1.01^{\mathrm{x}^{+}}$ & $19.72 \pm 0.92^{x^{+}}$ & $18.08 \pm 0.90^{\mathrm{x}+}$ & $17.06 \pm 0.85^{\mathrm{x}^{+}}$ & $17.03 \pm 0.85^{\mathrm{x}++}$ \\
\hline 85.32 & $48.46 \pm 2.16^{\mathrm{x}+}$ & $42.45 \pm 2.16^{\mathrm{x}^{+}}$ & $39.21 \pm 1.96^{\mathrm{x}+}$ & $36.58 \pm 1.82^{x^{+}}$ & $36.48 \pm 1.75^{\mathrm{x}++}$ \\
\hline 170.64 & $96.72 \pm 4.64^{\mathrm{x}++}$ & $84.67 \pm 4.14^{\mathrm{x}++}$ & $78.25 \pm 3.9^{\mathrm{x}++}$ & $72.9 \pm 3.64^{\mathrm{x}++}$ & $72.76 \pm 3.63^{\mathrm{x}++}$ \\
\hline 341.29 & $193.17 \pm 9.65^{\mathrm{x}++}$ & $169.07 \pm 7.60^{\mathrm{x}++}$ & $156.0 \pm 7.02^{\mathrm{x}++}$ & $145.56 \pm 6.98^{\mathrm{x}++}$ & $145.25 \pm 6.97^{\mathrm{x}++}$ \\
\hline Correlation & 0.96 & 0.97 & 0.97 & 0.98 & 0.99 \\
\hline \multicolumn{6}{|l|}{ Coefficient (r) } \\
\hline \multicolumn{6}{|c|}{ Biomass dosage (4 g) } \\
\hline $03.41 \mathrm{a}$ & $01.97 \pm 0.10^{\mathrm{bx}+\varphi}$ & $01.60 \pm 0.09^{x^{+}}$ & $01.39 \pm 0.07^{\mathrm{x}+}$ & $01.33 \pm 0.07^{\mathrm{x}^{+}}$ & $01.33 \pm 0.07^{\mathrm{xx}+}$ \\
\hline 17.06 & $08.49 \pm 0.45^{\mathrm{x}+}$ & $06.99 \pm 0.37^{x^{+}}$ & $06.14 \pm 0.34^{\mathrm{x}+}$ & $05.76 \pm 0.29^{x^{+}}$ & $05.76 \pm 0.29^{\mathrm{xx}+}$ \\
\hline 34.12 & $14.94 \pm 0.79^{x^{+}}$ & $12.49 \pm 0.66^{x^{+}}$ & $11.26 \pm 0.58^{\mathrm{x}+}$ & $10.22 \pm 0.52^{\mathrm{x}^{+}}$ & $10.20 \pm 0.51^{\mathrm{x}++}$ \\
\hline 85.32 & $32.80 \pm 1.73^{\mathrm{x}^{+}}$ & $26.05 \pm 1.38^{\mathrm{x}^{+}}$ & $22.78 \pm 1.13^{\mathrm{x}+}$ & $20.78 \pm 1.07^{\mathrm{x}^{+}}$ & $20.71 \pm 1.03^{\mathrm{x}++}$ \\
\hline 170.64 & $65.49 \pm 3.53^{\mathrm{x}++}$ & $52.01 \pm 2.80^{\mathrm{x}++}$ & $45.42 \pm 2.36^{\mathrm{x}++}$ & $41.39 \pm 2.06^{\mathrm{x}++}$ & $41.29 \pm 2.06^{\mathrm{x}++}$ \\
\hline 341.29 & $130.71 \pm 6.79^{x++}$ & $103.72 \pm 5.39^{\mathrm{x}++}$ & $90.61 \pm 4.80^{\mathrm{x}++}$ & $82.55 \pm 4.29^{\mathrm{x}++}$ & $82.32 \pm 4.11^{\mathrm{x}++}$ \\
\hline Correlation & 0.96 & 0.97 & 0.95 & 0.98 & 0.99 \\
\hline \multicolumn{6}{|l|}{ Coefficient(r) } \\
\hline \multicolumn{6}{|c|}{ Biomass dosage (6 g) } \\
\hline $03.41 \mathrm{a}$ & $01.97 \pm 0.11^{\mathrm{bx}+\varphi \varphi}$ & $01.60 \pm 0.09^{x^{+}}$ & $01.39 \pm 0.08^{\mathrm{x}+}$ & $01.33 \pm 0.07^{\mathrm{x}+}$ & $01.33 \pm 0.08^{\mathrm{x}++}$ \\
\hline 17.06 & $08.49 \pm 0.45^{\mathrm{x}^{+}}$ & $06.99 \pm 0.37^{\mathrm{x}^{+}}$ & $06.14 \pm 0.34^{\mathrm{x}+}$ & $05.76 \pm 0.29^{x^{+}}$ & $05.76 \pm 0.29^{\mathrm{xx}+}$ \\
\hline 34.12 & $14.94 \pm 0.76^{\mathrm{x}^{+}}$ & $12.49 \pm 0.67^{x^{+}}$ & $11.22 \pm 0.60^{\mathrm{x}+}$ & $10.20 \pm 0.53^{x^{+}}$ & $10.17 \pm 0.52^{\mathrm{x}++}$ \\
\hline 85.32 & $32.74 \pm 1.57^{x^{+}}$ & $25.98 \pm 1.35^{\mathrm{x}^{+}}$ & $22.68 \pm 1.22^{\mathrm{x}^{+}}$ & $20.71 \pm 1.11^{\mathrm{x}^{+}}$ & $20.64 \pm 1.07^{\mathrm{x}++}$ \\
\hline 170.64 & $65.35 \pm 3.59^{\mathrm{x}++}$ & $51.80 \pm 2.84^{\mathrm{x}++}$ & $45.25 \pm 2.39^{\mathrm{x}++}$ & $41.26 \pm 2.18^{\mathrm{x}++}$ & $41.12 \pm 2.17^{\mathrm{x}++}$ \\
\hline 341.29 & $130.30 \pm 6.25^{\mathrm{x}++}$ & $103.31 \pm 5.16^{\mathrm{x}++}$ & $90.23 \pm 4.51^{\mathrm{x}++}$ & $82.21 \pm 4.27^{\mathrm{x}++}$ & $82.01 \pm 4.26^{\mathrm{x}++}$ \\
\hline Correlation & 0.96 & 0.97 & 0.95 & 0.98 & 0.99 \\
\hline Coefficient (r) & & & & & \\
\hline
\end{tabular}

${ }^{\mathrm{a}}$ Number in parenthesis represent soluble metal concentration in $\mu \mathrm{M}$.,

${ }^{\mathrm{b}}$ Standard deviation values of replicate $(\mathrm{N}=5)$ determinations.

Mean difference [initial Ni(II) loaded $(\mu \mathrm{M})$ versus soluble Ni(II) $(\mu \mathrm{M})$ ] as functions of

Time ${ }^{x}$ significant $(\mathrm{p}<0.10),{ }^{\mathrm{xx}}$ insignificance $(\mathrm{p}>0.10)$.

Metal concentration ${ }^{+}$significance $(\mathrm{p}<0.10),{ }^{++}$insignificance $(\mathrm{p}>0.01)$.

Biomass dosage ${ }^{\varphi}$ significance $(\mathrm{p}<0.01),{ }^{\varphi \varphi}$ insignificance $(\mathrm{p}>0.01)$.

\subsection{Optimization of the ANN Structure}

The prediction of removal efficiency of $\mathrm{Ni}(\mathrm{II})$ ions from aqueous system using SMOS are made in the range of metal concentration with which experiments have not been conducted. A training set of ninety experimental data sets was selected to develop the model. ANN model based on single layer recurrent back propagation algorithm for the experimental data was applied to train the neural network. During training, the output vector is computed by a forward pass in which the input is propagated forward through the network to compute the output value of each unit. The output vector is then compared with the desired vector which resulted into error signal for each output unit. In order to minimize the error, appropriate adjustments were made for each of the weights of the network. After several such iterations, the network was trained to give the desired output for a given input 
vector. The optimum network structure was determined as single layer with 10 hidden neurons (1000 epochs) describing the dynamics of $\mathrm{Ni}(\mathrm{II})$ in effluent (Figure 1) respectively.

The sigmoid axon was considered transfer function with 0.7 momentums. The performance of neural network simulation was evaluated in terms of mean squared error (MSE) criterion. The MSE for the training and cross validation data sets were found at the ninth place of decimal. The developed network model was examined for its ability to predict the response of experimental data not forming part of the training program. Figure 2 show the result obtained by the network simulation for both the training and cross validation data sets. The reduction in Ni(II) concentrations were precisely predicted for the training data sets. The development of the proposed ANN model is an effort towards the growing interest in applying ANN modeling technique to the area of biosorption of pollutants from water bodies [21-23].

\subsection{Sensitivity Analysis}

A sensitivity analysis was conducted to determine the degree of effectiveness of variables. Performance of the groups of input vectors included biomass dosage, Ni(II) ion concentration, contact time and volume of test solution. Series of experiment resulted into the evaluation of the performance based on $50 \%$ data for training, $25 \%$ data for testing and $25 \%$ data for cross validation at 1000 Epoch with 0.70000 momentums. The minimum MSE in the group of four variables determined for training and cross validation were 0.005956571 and 0.00866526823 respectively as shown in the Table 2 .

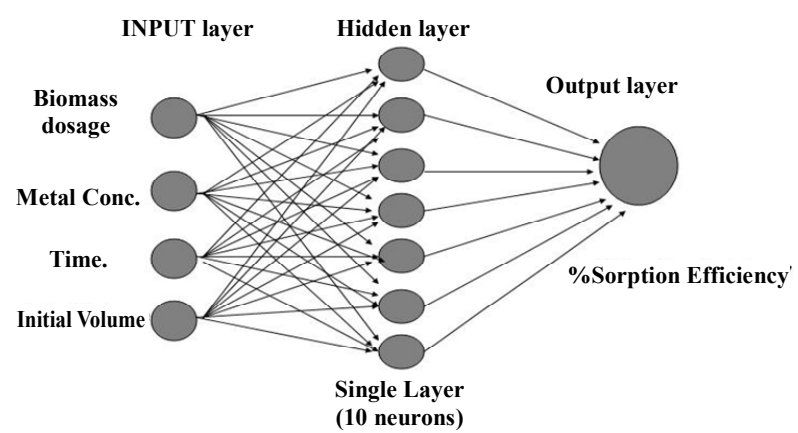

Figure 1. Single layer Neural Network structure for the prediction of the biosorption efficiency.

Table 2. Minimum MSE.

\begin{tabular}{ccc}
\hline Best Networks & Training & Cross Validation \\
\hline Run \# & 5 & 4 \\
Epoch \# & 1000 & 1000 \\
Minimum MSE & 0.00595657 & 0.008652682 \\
Final MSE & 0.00595657 & 0.008652682 \\
\hline
\end{tabular}

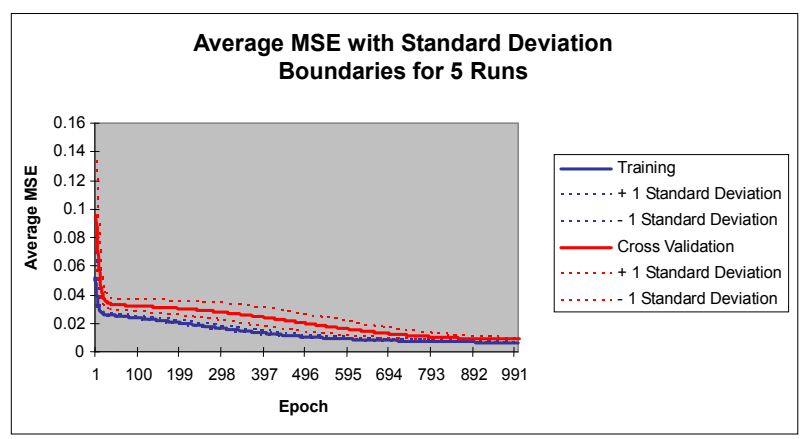

(a)

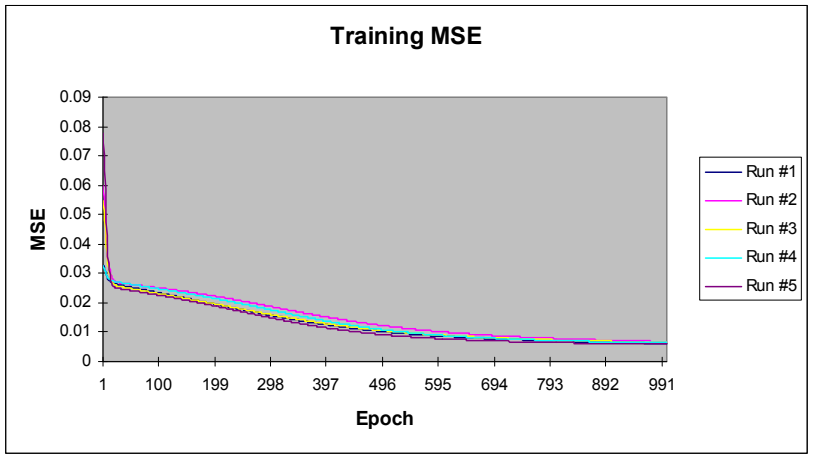

(b)

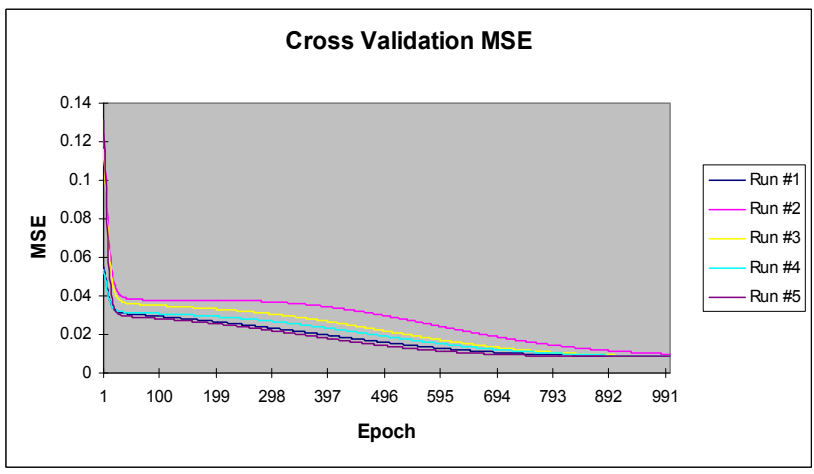

(c)

Figure 2. Graphical representation of MSE value with 1000 Epoch.

The effect of various experimental parameters was studied and compared with performance of ANN model based predictions.

\subsection{Effect of Metal Concentration on the Sorption Efficiency}

Figure 3 represents the effect of metal concentration on the sorption behavior of Ni(II) on SMOS in the range of metal concentration (10-100 mg/L). Sorption of Ni(II) on SMOS increased with increasing concentration of the metal ion reaching to an optimal level $(25 \mathrm{mg} / \mathrm{L})$. Later, an increase in initial concentration decreased the percentage binding. These observations can be explained by 

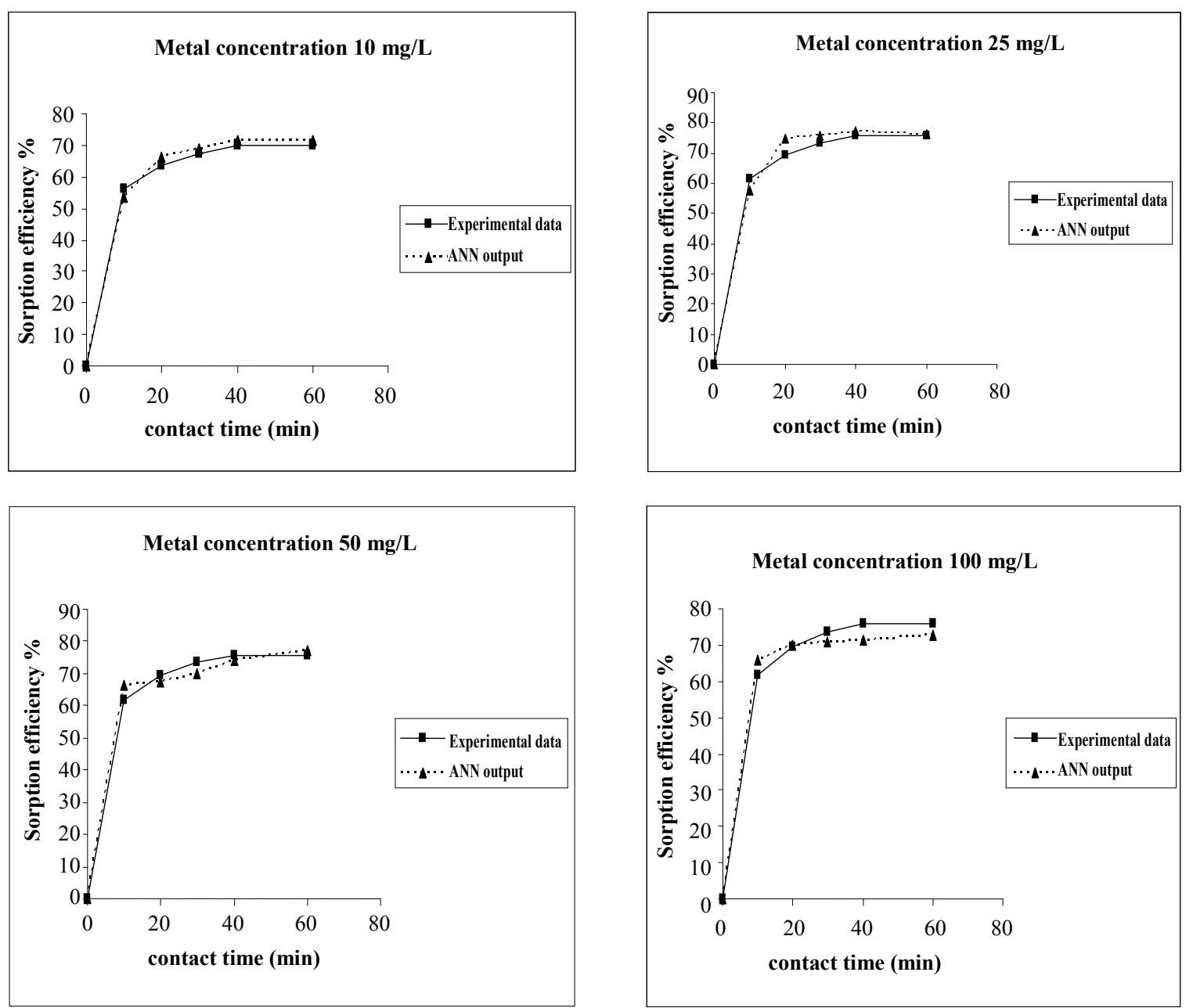

Figure 3. Agreement between ANN outputs and experimental data as a function of metal concentration (biomass dosage $=4.0$ $\mathrm{g}$, volume $=200 \mathrm{~mL}$ and $\mathrm{pH}=6.5)$.

the fact that at medium concentrations, the ratio of sorptive surface area to metal ions available is high and thus, there is a greater chance for metal removal. When metal ion concentrations are increased, binding sites become more quickly saturated as the amount of biomass concentration remained constant [23]. The experimental data and ANN calculated outputs were compared and found that the ANN model shows a good performance on prediction of the experimental data.

\subsection{Effect of Biomass Dosage on the Sorption Efficiency}

Percent sorption increased with the increase of biomass dosage from 2.0 to $6.0 \mathrm{~g}$. However, no significant increment in the sorption tendency was observed on further increasing the biomass dosage from $4.0 \mathrm{~g}$ onwards. This might be due to attainment of equilibrium between adsorbate and adsorbent at the existing operating conditions rendering adsorbent incapable of further adsorption. The amount of biomaterial ( $4.0 \mathrm{~g})$ used in present case seems to be quite reasonable, as practically similar biosorption efficiencies for the same set of metals were reported with relatively higher biomaterial dosage from 6.0 to $10.0 \mathrm{~g}$ of different biosorbents like Okra wastes [24] and Nile rosa [25]. The perusal of experimental data and ANN outputs as a function of biomass dosages (Figure 4) depicted the performance of the model in good harmony with the experimental data.

\subsection{Effect of Initial Volume on the Sorption Efficiency}

The effect of volume on the percent sorption of $\mathrm{Ni}$ (II) on SMOS was observed under similar experimental conditions in different set of volumes (100-300 mL). Maximum sorption was obtained in the volume $(200 \mathrm{~mL})$ of the test solution. It shows that the ratio of sorption sur- 
face of the SMOS to total $\mathrm{Ni}(\mathrm{II})$ ions availability is optimum, exhibiting maximum percentage removal (75.64\%). ANN model showed performance in resemblance with experimental data (Figure 5).
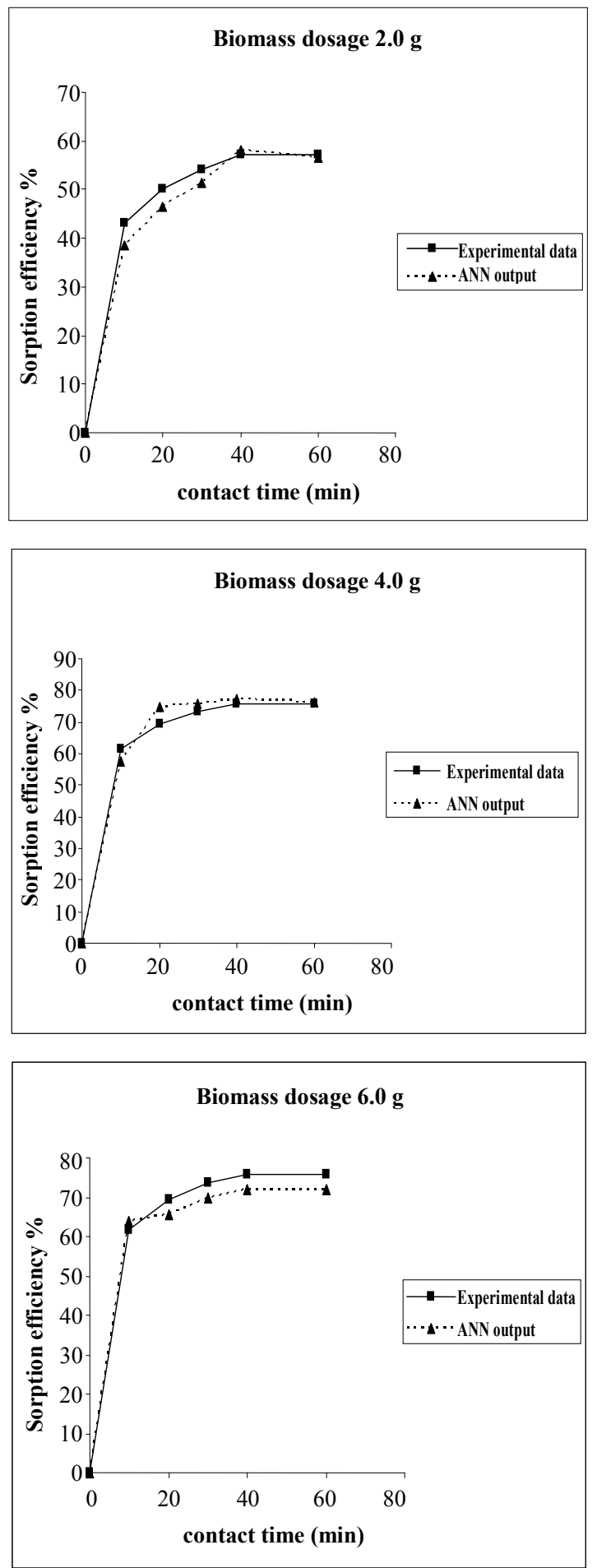

Figure 4. Agreement between ANN outputs and experimental data as a function of biomass dosage (metal concentration = $25 \mathrm{mg} / \mathrm{L}$, volume $=200 \mathrm{~mL}$ and $\mathrm{pH}=6.5$ ).
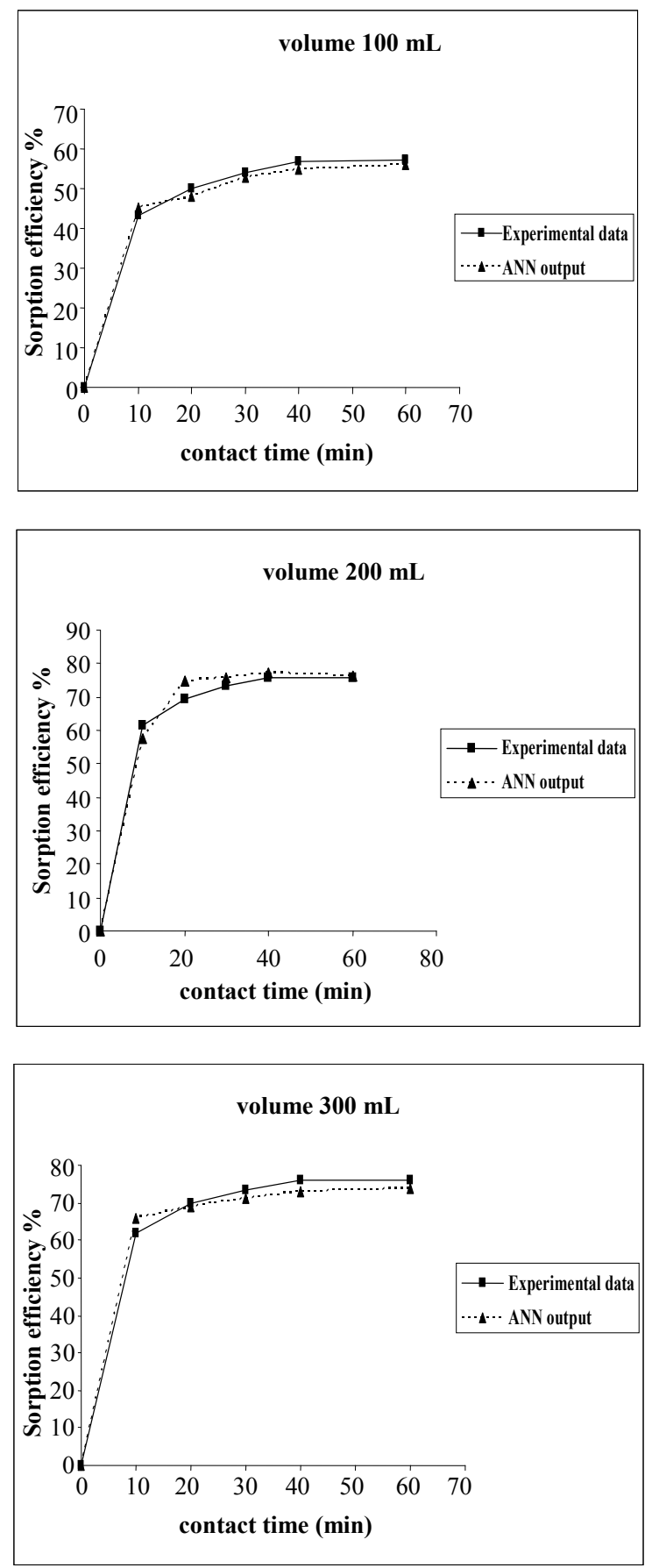

Figure 5. Agreement between ANN outputs and experimental data as a function of volume (metal concentration $=\mathbf{2 5}$ $\mathrm{mg} / \mathrm{L}$, biomass dose $=4.0 \mathrm{~g}$ and $\mathrm{pH}=6.5$ ).

\subsection{Effect of Contact Time on the Sorption Efficiency}

The effect of contact time on Ni(II) sorption on SMOS was studied for duration of 10-60 minutes. The percent sorption metal ion gradually increased with time from 10 to 30 minutes, finally reaching the optimum value at 40 
minutes. Once equilibrium was attained, the percentage sorption of $\mathrm{Ni}$ (II) ion did not change with further increase of time. On comparison basis, sorption efficiency of the present process is much better than earlier reported contact time ranging from 60 to 120 minutes for same metals shown by other agricultural byproducts such as corn cob [26] and Rice husk [27]. ANN model prediction was found in match with experimental data.

\subsection{Effect of pH on Sorption Efficiency}

The $\mathrm{pH}$ of a suspension is an important factor that can affect the percentage sorption of $\mathrm{Ni}$ (II) ion on SMOS. The sorption efficiency increases, as the $\mathrm{pH}$ of the solution is increased from 4.5 to 8.5 . The $\mathrm{pH}$ profile for $\mathrm{Ni}$ (II) sorption on seed powder shows that metal sorption is a function of $\mathrm{pH}$, exhibiting maximum sorption at $\mathrm{pH} 6.5$. There was no significant difference in sorption behavior with further increase in $\mathrm{pH}$ up to 7.5. Investigation on $\mathrm{pH}$ variation beyond 7.5 yielded an increase in sorption up to $\mathrm{pH} 8.5$ which might be due to the precipitation carry over of $\mathrm{Ni}$ (II) ion which starts at $\mathrm{pH} 7.5$ [28]. As the $\mathrm{pH}$ of the solution increases from 4.5 to $7.5, \mathrm{Ni}$ (II) ion reflects increased binding behavior to the biomass with optimum binding at $\mathrm{pH}$ 6.5. SMOS seed powder prominently contains low molecular weight amino acid. Amino acids have been found to constitute a physiologically active group of transporters, working even at low concentration, which because of ability to interact with metal ions is likely to increase their mobility [29]. These Proteinaceous amino acids have variety of structurally related $\mathrm{pH}$ dependent properties of generating appropriate atmosphere (positively and/or negatively charged sites) for attracting the cationic and anionic species of metal ions [30]. Therefore, ANN model predictions were made at optimum $\mathrm{pH} 6.5$.

\section{Conclusions}

The present piece of work demonstrates the successful removal of $\mathrm{Ni}$ (II) ions from the aqueous solutions using Moringa Oleifera seeds with maximum removal efficiency (75.64\%). The single layer ANN modeling technique was applied to optimize this process. The Levenberg-Marquardt algorithm (LMA) was found best of BP algorithms with a minimum mean squared error (MSE) for training and cross validation as 0.005956571 and 0.0086526823 respectively. Thus a simple back propagation of the recurrent network using the momentum training algorithm is proved meaningful supplement for the conventional and complicated mathematical models in the prediction of bioprocess. Introduction of knowledge-based systems is efficient for scientific research of unstudied dependence among different by natural variables (physical, chemical, biological) for solving tasks of inferential measurement and process optimization without requiring a big amount of precise experimental data.

\section{Acknowledgements}

The authors gratefully acknowledge Prof. V.G. Das, Director and Prof. L.D. Khemani, Head, Department of Chemistry, Dayalbagh Educational Institute, Dayalbagh, Agra for providing necessary facilities. Dr. Sandeep Paul, Technical College, Dayalbagh Educational Institute is also acknowledged for fruitful scientific discussions.

\section{References}

[1] R. Nadeem, M. A. Hanif, F. Shaheen, M. N. Perveen Zafar and T. Iqbal, "Physical and Chemical Modification of Distillery Sludge for $\mathrm{Pb}(\mathrm{II})$ Biosorption," Journal of Hazardous Materials, Vol. 150, No. 2, January 2008, pp. 335-342.

[2] Y.-K. Chang, J.-E. Chang, T.-T. Lin and Y.-M. Hsu, "Integrated Copper Containing Waste Water Treatment Using Xanthate Process," Journal of Hazardous Materials, Vol. 94, No. 1, 2 September 2002, pp. 89-99.

[3] S. J. Park and Y. S. Jang, "Pore Structure and Surface Properties of Chemically Modified Activated Carbons for Adsorption Mechanism and Rate of Cr(VI)," Journal of Colloid and Interface Science, Vol. 249, No. 2, 15 May 2002, pp. 458-463.

[4] R. A. Rao and M. A. Khan, "Biosorption of Bivalent Metal Ions from Aqueous Solution by an Agricultural Waste: Kinetics, Thermodynamics and Environmental Effects," Colloids and Surfaces A: Physicochemical and Engineering Aspects, Vol. 332, No. 2-3, 15 January 2009, pp. 121-128.

[5] A. H. Hawari, C. N. Mulligan, "Biosorption of $\mathrm{Pb}(\mathrm{II}), \mathrm{Cd}$ (II), $\mathrm{Cu}(\mathrm{II})$ and $\mathrm{Ni}(\mathrm{II})$ by Anaerobic Granular Biomass," Bioresource Technology, Vol. 97, No. 4, March 2006, pp. 692-700.

[6] V. Isabel, V. Nuria, V. Maria, M. Nuria, P. Jordi and S. Joan, "Grapes Stalks Waste as Low Cost Biosorbents: An Alternative for Metal Removal from Aqueous Solutions," Water Research, Vol. 38, 2004, pp. 992-1002.

[7] S. R. Shukla and S. P. Roshan, "Removal of Heavy Metals by Jute Fibres," Bioresourse Technology, Vol. 96, No. 2, 2005, pp.1430-1438.

[8] F. Pagnanelli, L. Toro and M. Sara, "Removal and Recovery of $\mathrm{Ni}(\mathrm{II}), \mathrm{Pb}(\mathrm{II})$ and $\mathrm{Cr}(\mathrm{III})$ by Olive Mill Residue," Environmental Science and Technology, Vol. 15, 2002, pp. 47-59.

[9] K. Periasamy and C. Namasivayam, "Removal of Ni (II) from Aqueous Solution and Nickel Plating Industry Wastewater Using an Agricultural Waste: Peanut Hulls," Waste Management, Vol. 15, No. 1, 1995, pp. 63-68.

[10] M. Ronteltap, M. Maurer and W. Gujer, "The Behavior of Pharmaceuticals and Heavy Metals during Struvite Precipitation in Urine," Water Research, Vol. 41, No. 9, 
May 2007, pp. 1859-1868.

[11] P. P. Vishwakarma, K. P. Yadava and V. N. Singh, "Nickel(II) Removal from Aqueous Solutions by Adsorption on Fly Ash," Pertanika, Vol. 12, 1989, pp.357-366.

[12] N. Akhtar, J. Iqbal and M. Iqbal, "Removal and Recovery of Nickel(II) from Aqueous Solution by Loofa Sponge-Immobilized Biomass of Chlorella Sorokiniana: Characterization Studies," Journal of Hazardous Materials, Vol. 108, No. 1-2, April 2004, pp. 85-94.

[13] W. Saha and K. L. Edwards, "The Use of Artificial Neural Networks in Material Science Based Research," $M a$ terials Design, Vol. 28, No. 6, 2007, pp. 1747-1752.

[14] P. Rai, G. C. Majumdar, S. Das Gupta and S. De, "Modeling the Performance of Batch Ultra Filtration of Synthetic Fruit Juice and Mosambi Juice Using Artificial Neural Network," Journal of Food Engineering, Vol. 71, No. 3, December 2005, pp.273-281.

[15] A. Abbas and N. Al-Bastaki, "Modeling of an RO Water Desalination Unit Using Neural Network," Chemical Engineering Journal, Vol. 114, No. 1-3, November 2005, pp. 139-143.

[16] A. Shahavand and M. P. Chenar, "Neural Network Modeling of Hollow Fiber Membrane Processes," Journal of Membrane Science, Vol. 297, No. 1-2, July 2007, pp. 59-73.

[17] P. Sharma, P. Kumari, M. M. Srivastava and S. Srivastava, "Biosorption Studies on Shelled Moringa Oleifera Lamarck Seed Powder: Removal and Recovery of Arsenic from Aqueous System," International Journal of Mineral Processing, Vol. 78, No. 3, February 2006, pp. 131-139.

[18] P. Sharma, P. Kumari, M. M. Srivastava and S. Srivastava, "Ternary Biosorption Studies of Cd(II), Cr(III) and Ni(II) on Shelled Moringa Oleifera Seeds," Bioresourse Technology, Elsevier, Vol. 98, No. 2, January 2007, pp. 474477.

[19] P. Sharma, P. Kumari, M. M. Srivastava and S. Srivastava, "Removal of Cd from Aqueous System by Shelled Moringa Oleifera Lamarck Seed Powder," Bioresourse Technology, Elsevier, Vol. 97, No. 2, 2006, pp.299-305.

[20] P. Sharma, P. Goyal and S. Srivastava, "Biosorption of Trivalent and Hexavalent Chromium from Aqueous System Using Shelled Moringa Oleifera Seeds," Chemical Speciation and Bioavailability, Vol. 19, No. 4, November 2007, pp. 185-191.

[21] A. C. Texier, Y. Andres, C. Faur-Brasquet and P. Le
Cloirec, "Fixed-bed Study for Lanthanide (La, Eu, Yb) Ions Removal from Aqueous Solutions by Immobilized Pseudomonas Aeruginosa: Experimental Data and Modelization," Chemosphere, Vol. 47, No. 3, April 2002, pp. 333-342.

[22] K. H. Chu, "Prediction of Two-Metal Biosorption Equilibria Using a Neural Network," European Journal of Mineral Processing and Environmental Protection, Vol. 3, No. 1, 2003, pp. 119-127.

[23] K. Yetilmezsoy and S. Demirel, "Artificial Neural Network (ANN) Approach for Modeling of Pb (II) Adsorption from Aqueous Solution by Antep Pistachio (Pistacia Vera L.) Shells," Journal of Hazardous Materials, Vol. 153, No. 3, May 2008, pp. 1288-1300.

[24] M. A. Hashem, "Adsorption of Lead Ions from Aqueous Solution by Okra Wastes," International Journal of Physical Science, Vol. 2, No. 7, 2007, pp. 178-184.

[25] N. T. Abdel-Ghani and G. A. Elchaghaby, "Influence of Operating Conditions on the Removal of $\mathrm{Cu}, \mathrm{Zn}, \mathrm{Cd}$ and $\mathrm{Pb}$ Ions from Wastewater by Adsorption," International Journal of Environmental Science and Technology, Vol. 4, No. 4, 2007, pp. 451-456.

[26] H. Parmar, J. Patel, P. Sudhakar and V. J Koshi, "Removal of Fluoride from Water with Powdered Corn cobs," Journal of Environmental Science and Engineering, Vol. 48, No. 2, 2006, pp. 135-138.

[27] N. T. Abdel-Ghani, M. Hefny and G. A. F. El-Chaghaby, "Removal of Lead from Aqueous Solution Using Low Cost Abundantly Available Adsorbents," International Journal of Environmental Science and Technology, Vol. 4, No. 1, 2007, pp. 67-73.

[28] M. Iqbal, A. Saeed and N. Akhtar, "Petiolar Felt-Shealth of Palm: A New Biosorbent for the Removal of Heavy Metals from Contaminated Water," Bioresourse Technology, Vol. 81, No. 2, January 2002, pp. 151-153.

[29] A. C. Brostlap and J. Schuurmans, "Kinetics of L-valine Uptake in Tobacco Leaf Disc. Comparison of Wild-Type, the Digenic Mutant $\mathrm{Val}^{\mathrm{r}}-2$, and its Monogenic Derivatives," Planta, Vol. 176, No. 1, November 1988, pp. 4250.

[30] G. Costa, J. C. Michant and A. Guckert, "Amino Acids Exuded from Axenic Roots of Lettuce and White Lupin Seedlings Exposed to Different Cadmium Concentrations," Journal of Plant Nutrition, Vol. 20, No. 7-8, 1997, pp. 883-900. 